\title{
Scanning the Future-Ultrasonography as a Reproductive Management Tool for Dairy Cattle ${ }^{1}$
}

\author{
P. M. Fricke \\ Department of Dairy Science, \\ University of Wisconsin, Madison 53706
}

\begin{abstract}
Application of transrectal real-time ultrasonography as a research tool to study bovine reproduction represents a technological breakthrough that has revolutionized our understanding of reproductive biology in cattle. The widespread adoption and use of ultrasonography for routine reproductive examinations of dairy cattle by bovine practitioners is the next contribution this technology will make to the dairy industry. Assessment of pregnancy status and fetal viability early postbreeding to identify cows that fail to conceive improves reproductive efficiency by decreasing the interval between artificial insemination services and increasing artificial insemination service rate. Early identification of cows carrying twin fetuses will allow for implementation of differential management strategies to abrogate negative effects of twinning during the periparturient period once such strategies have been developed. Ovarian and uterine pathologies not accurately detected via rectal palpation can easily be visualized by ultrasound, and appropriate therapies can be implemented. Determination of fetal sex in utero is useful when coupled with a management decision that justifies the expense of fetal sexing. Development of integrated reproductive management systems that combine ultrasound with new and existing reproductive technologies will further enhance the practical applications of ultrasonography. Development of Extension education programs to train bovine practitioners to use ultrasound for routine reproductive examinations is a critical step toward rapid implementation of this technology into the dairy industry.
\end{abstract}

(Key words: ultrasound, dairy cattle, reproductive management)

\footnotetext{
Received July 13, 2001.

Accepted October 4, 2001.

e-mail: fricke@calshp.cals.wisc.edu.

${ }^{1}$ This paper was presented at the "Applications of Ultrasound in Livestock Production Systems" symposium at the Joint ADSA/ASAS meeting in Indianapolis, IN, July 27, 2001.
}

\section{INTRODUCTION}

The application of transrectal real-time ultrasonography to the study of bovine reproduction represents a technological breakthrough that has revolutionized knowledge of reproductive biology. New research information generated through ultrasonic imaging has clarified the nature of complex reproductive processes in cattle including ovarian follicular dynamics, corpus luteum function, and fetal development. Early integration of ultrasound technology to the dairy industry included applications such as transvaginal follicular aspiration and oocyte recovery (Pieterse et al., 1988; Pieterse et al., 1991; Meintjes et al., 1993) and as a complementary technology for embryo transfer procedures. These applications are, however, specialized and will not likely constitute widespread use of ultrasound technology in the dairy industry. The purpose of this review is to examine practical applications of ultrasound to the dairy industry that may constitute widespread use of this technology in the future.

Practical applications of ultrasound include early assessment of pregnancy status, identification of cows carrying twin fetuses, detection of ovarian and uterine pathologies, and determination of fetal sex. Each of these applications presents opportunities for improving reproductive efficiency on a dairy farm. Unfortunately, most veterinary students continue to be taught that ultrasound is a secondary technology for bovine reproductive work; however, the information-gathering capabilities of ultrasonic imaging far exceed those of rectal palpation (Ginther, 1995). Extension education programs to train bovine practitioners to use ultrasound for routine reproductive examinations are a critical step toward rapid implementation of this technology into the dairy industry.

\section{Veterinary Ultrasound Equipment}

Detailed information on the principles of ultrasonography is beyond the scope of this review and has been reviewed elsewhere (Ginther, 1995). In general, lineararray, real-time, B-mode (brightness modality) ultrasound scanners are best suited for veterinary applica- 
tions involving dairy cattle reproduction. Most ultrasound machines consist of a console unit that contains the electronics, controls, and a screen upon which the ultrasound image is visualized by the operator, and a transducer, which emits and receives high-frequency ultrasound waves. Linear-array transducers consist of a series of piezo electric crystals arranged in a row. These crystals emit high frequency sound waves upon being energized. The configuration of a linear-array transducer results in a rectangular image on the field of scan (as opposed to a pie shaped image produced by a sector transducer). Currently, a veterinary-grade ultrasound machine equipped with one rectal transducer can be purchased for $\$ 8000$ to $\$ 16,000$. Image quality varies widely among veterinary-grade ultrasound machines and generally increases with the cost of the unit. More expensive machines are available but are not necessary for routine reproductive examinations in dairy cattle.

Bovine reproductive organs are most commonly scanned per rectum using a linear-array transducer specifically manufactured for transrectal use. However, specialized applications including ovum pickup and follicle ablation involve a transvaginal approach using a sector transducer. Linear-array transducers of 5.0 and $7.5 \mathrm{MHz}$ frequency ranges are most commonly used in cattle to perform reproductive ultrasound examinations, and most veterinary ultrasound scanners are compatible with probes of different frequencies. The depth of tissue penetration of sound waves and image resolution is dependent upon and inversely related to the frequency of the transducer. Thus, a 5.0-MHz transducer results in greater depth of tissue penetration and lesser image detail, whereas a 7.5-MHz transducer results in lesser depth of tissue penetration and greater image detail. An ultrasound scanner equipped with a $5.0-\mathrm{MHz}$ transducer is most useful for bovine practitioners conducting routine reproductive examinations; however, small ovarian structures such as developing follicles are best imaged with a $7.5-\mathrm{MHz}$ transducer.

\section{IMAGING THE BOVINE OVARY}

\section{Ovarian Follicles}

Folliculogenesis is the process of forming mature follicles capable of ovulation from the pool of nongrowing, primordial follicles in the ovary (Spicer and Echternkamp, 1986). Ovarian follicles are fluid-filled structures surrounded by an inner layer of granulosa cells and an outer layer of thecal cells. The oocyte is suspended within the antrum by a specialized pedicle of granulosa cells called the cumulus oophorous. Because fluid absorbs rather than reflects ultrasound waves, fluid-filled structures such as antral follicles appear as black circular structures surrounded by echogenic ovarian tissue. Most veterinary grade ultrasound scanners can resolve ovarian follicles with a diameter of 2 to $3 \mathrm{~mm}$ or greater, and larger antral follicles can easily be tracked during serial scanning sessions (Pierson and Ginther, 1988).

\section{Corpora Lutea}

The CL is a transient endocrine gland that forms after ovulation from the tissues that previously constituted the ovarian follicle. Thus, the CL can be viewed as the terminal stage of follicular development. Corpora lutea appear as distinctly echogenic areas within the ovarian stroma. Many corpora lutea appear as a solid tissue masses but may also contain fluid-filled cavities. Based on ultrasonographic examinations in dairy heifers, $79 \%$ of otherwise normal CL contain cavities ranging from less than 2 to greater than $10 \mathrm{~mm}$ in diameter at some time during the estrus cycle and early pregnancy (Kastelic et al., 1990b; Singh et al., 1997). Ovarian cysts containing luteinized tissue should not be confused with a normal CL containing a fluid-filled cavity.

Ultrasonographic attributes of CL including crosssectional diameter, luteal area, and echogenicity have been correlated to luteal structure and function (Kastelic et al., 1990a; Singh et al., 1997; Battocchio et al., 1999). Use of luteal characteristics to improve the accuracy of pregnancy diagnosis has been reported in dairy heifers (Kastelic et al., 1991), but similar data have not been reported for lactating dairy cows. Luteal size and echogenic characteristics assessed at specific times postbreeding may prove useful as a method to improve the accuracy of early pregnancy diagnosis in dairy and beef cattle. Although ultrasound is more accurate than rectal palpation for assessing ovarian follicles, it is difficult to distinguish between developing corpora lutea and older regressing corpora lutea using either technique (Pieterse et al., 1990b).

\section{Ovarian Cysts}

Currently, diagnosis of cysts in cattle most often occurs during routine postpartum rectal examinations conducted by a bovine practitioner. Palpation per rectum of a large, fluid-filled structure is commonly used as a clinical indication of a follicular cyst. Differentiation between follicular and luteal cysts via rectal palpation is difficult, even for experienced practitioners (Dawson, 1975; Farin et al., 1992). Accuracy of diagnosis increases when using transrectal ultrasonography, with correct identification of greater than $90 \%$ of luteal and nearly $75 \%$ of follicular cysts (Farin et al., 1990, 1992). 
Table 1. Day of first detection of ultrasonographically identifiable characteristics of the bovine conceptus. ${ }^{1}$

\begin{tabular}{lll}
\hline & \multicolumn{2}{c}{ First day detected } \\
\cline { 2 - 3 } Characteristic & Mean & Range \\
\hline Embryo proper & 20.3 & 19 to 24 \\
Heartbeat & 20.9 & 19 to 24 \\
Allantois & 23.2 & 22 to 25 \\
Spinal cord & 29.1 & 26 to 33 \\
Forelimb buds & 29.1 & 28 to 31 \\
Anmion & 29.5 & 28 to 33 \\
Eye orbit & 30.2 & 29 to 33 \\
Hindlimb buds & 31.2 & 30 to 33 \\
Placentomes & 35.2 & 33 to 38 \\
Split hooves & 44.6 & 42 to 49 \\
Fetal movement & 44.8 & 42 to 50 \\
Ribs & 52.8 & 51 to 55 \\
\hline
\end{tabular}

${ }^{1}$ Adapted from Curran et al., 1986.

\section{Ovarian Structures as Diagnostic Aids}

A thorough reproductive examination in cattle includes visualization of the major structures (or the lack thereof) on both ovaries. Although rectal palpation can be an accurate method for diagnosing pregnancy, rectal palpation is a poor method for resolving ovarian follicles (Pieterse et al., 1990b). By contrast, ultrasonic imaging is a highly accurate and rapid method for assessing ovarian structures (Griffin and Ginther, 1992). Too often, bovine practitioners proceed directly to scanning the uterus during reproductive examinations and neglect the ovaries all together. This is unfortunate because the ovaries contain a wealth of information that can be used to aid in diagnosing the reproductive status of the cow and for selecting appropriate therapies or reproductive interventions. For example, the presence or absence of a corpus luteum aids in diagnosing pregnancy status, especially when conducting pregnancy exams early postbreeding. When present, the size and location (i.e., left vs. right ovary) of the corpus luteum indicate the location of the conceptus within the uterus if the cow is pregnant. Because most twinning in cattle is dizygotic (Fricke, 2001), the presence of multiple corpora lutea is a diagnostic indicator for cows at risk for conceiving twins. Ovarian pathologies and dysfunction including "static ovaries" (e.g., ovaries of anovular cows with no discernable follicular or luteal structures) and follicular and luteinized cysts can easily be distinguished.

\section{IMAGING THE BOVINE UTERUS AND CONCEPTUS}

Detection of the embryo proper as well as embryonic and fetal developmental characteristics during early fetal development are shown in Table 1. The bovine fetus can be visualized beginning at $20 \mathrm{~d}$ postbreeding and continuing throughout gestation. However, because of its size in relation to the image field of view, the fetus cannot be imaged in toto after about $90 \mathrm{~d}$ with a $5.0-\mathrm{MHz}$ linear-array transducer.

\section{Early Pregnancy Diagnosis}

The use of transrectal ultrasonography to assess pregnancy status early during gestation is among the most practical applications of ultrasound for dairy cattle reproduction. Early identification of nonpregnant cows postbreeding improves reproductive efficiency and pregnancy rate in cattle by decreasing the interval between AI services and increasing AI service rate. Pregnancy diagnosis in dairy heifers based on the presence of intraluminal uterine fluid before d 16 is unreliable because small amounts of fluid are present in noninseminated heifers as early as d 10; however, accuracy of diagnosis based on fluid alone approached $100 \%$ by d 20 . The accuracy of pregnancy diagnosis in dairy heifers was not greater than $50 \%$ before $d 18$ with a $5.0-\mathrm{MHz}$ transducer, or before d 16 with a $7.5-\mathrm{MHz}$ transducer (Kastelic et al., 1991).

Under most on-farm conditions, pregnancy diagnosis can be rapidly and accurately diagnosed using ultrasound as early as $26 \mathrm{~d}$ post AI (Kastelic et al., 1991; Filteau and DesCôteaux, 1998). Sensitivity and specificity of pregnancy diagnosis with ultrasound was 44.8 and $82.3 \%$, respectively, when conducted between 21 and $25 \mathrm{~d}$ post AI but increased to 97.7 and $87.7 \%$, respectively, when conducted between 26 and $33 \mathrm{~d}$ post AI (Pieterse et al., 1990a). Although pregnancy status can be established early, care must be taken to ensure the accuracy of a diagnosis. For example, a false-negative diagnosis was more likely when the uterus was located cranial to the pelvic inlet in beef cattle than when the uterus was within the pelvic cavity (Szenci et al., 1995).

Ultrasound is a rapid method for pregnancy diagnosis, and experienced palpators adapt to ultrasound technology quickly. The time required to assess pregnancy in beef heifers at the end of a 108-d breeding season averaged $11.3 \mathrm{~s}$ using palpation per rectum versus 16.1 $\mathrm{s}$ required to assess pregnancy and fetal age using ultrasound (Galland et al., 1994). Fetal age also affected time required for diagnosis with older fetuses requiring less total time for diagnosis (Galland et al., 1994). Although ultrasound at $\geq 45 \mathrm{~d}$ of gestation did not increase the accuracy of pregnancy diagnosis for an experienced palpator, it may improve diagnostic accuracy of a less experienced one (Galland et al., 1994). Generally, two factors affect the speed at which ultrasound examinations can be conducted on a dairy farm: operator proficiency and availability and restraint of animals. When 
both factors are optimized, the speed of ultrasonography can approach that of palpation, while exceeding palpation in the amount of information gathered from each animal.

\section{Early Embryonic Loss}

Pregnancy loss contributes to reproductive inefficiency because fertility assessed at any point during pregnancy is a function of both conception rate and pregnancy loss. Conception rates at 28 to $32 \mathrm{~d}$ post AI in lactating dairy cows range from 40 to $47 \%$ (Pursley et al, 1997; Fricke et al., 1998), whereas, conception rates in dairy heifers are nearly $75 \%$ (Pursley et al., 1997). Similarly, pregnancy loss in lactating dairy cows is greater than that in dairy heifers (20 vs. 5\%; Smith and Stevenson, 1995). Although the specific factors responsible for early embryonic loss in dairy cows are not known, they may be similar to those factors responsible for reduced conception rates.

Because pregnancy status can be determined earlier by ultrasound compared with palpation, the rate of pregnancy loss detected is often higher when a positive diagnosis is made earlier postbreeding. Of cows diagnosed pregnant at $28 \mathrm{~d}$ post $\mathrm{AI}, 10$ to $16 \%$ experience early embryonic loss by 56 d post AI (Mee et al., 1994; Vasconcelos et al., 1997; Fricke et al., 1998). Therefore, cows diagnosed pregnant at $28 \mathrm{~d}$ post AI using ultrasound should be scheduled for a subsequent examination around $60 \mathrm{~d}$ post AI, when the rate of embryonic loss per day decreases dramatically (Vasconcelos et al., 1997). Although the rate of pregnancy loss is significant in studies using ultrasound to assess the rate of loss, the technique of ultrasound itself has not been implicated as a cause of embryonic death in cattle (Ball and Logue, 1994; Baxter and Ward, 1997). Furthermore, ultrasound is a much less invasive technique for early pregnancy diagnosis than is rectal palpation (Paisley et al., 1978; Vaillancourt et al., 1979) and may minimize the rare incidence of palpation-induced abortions.

At present, there is no practical way to reduce early embryonic loss in lactating dairy cows. However, recognizing the occurrence and magnitude of early embryonic loss may actually present management opportunities by taking advantage of new reproductive technologies that increase AI service rate in a dairy herd. If used routinely, transrectal ultrasonography has the potential to improve reproductive efficiency within a herd by reducing the period from $\mathrm{AI}$ to pregnancy diagnosis to 26 to $28 \mathrm{~d}$ with a high degree of diagnostic accuracy (Pieterse et al., 1990a). Early pregnancy diagnosis can, however, only improve reproductive efficiency when a nonpregnancy diagnosis is coupled with a management strategy to rapidly return cows to AI service, and such strategies have not yet been empirically tested for their effects on conception rate. In addition, cows diagnosed pregnant at an early ultrasound exam have a greater risk of early embryonic loss and, therefore, must undergo subsequent pregnancy examinations to identify and rebreed cows that experience such loss. If left unidentified, cows experiencing embryonic loss after an early pregnancy diagnosis would actually reduce reproductive efficiency by extending their calving interval. This concept applies not only to ultrasound, but also to any method used to assess pregnancy status early post breeding.

\section{Identification of Cows Carrying Twins}

Twinning is an unavoidable outcome of reproduction in dairy cattle and is undesirable because it reduces overall dairy farm profitability and reproductive efficiency (Eddy et al., 1991; Beerepoot et al., 1992). The reported incidence of twinning in dairy cattle ranges from 2.5 to $5.8 \%$ and is dramatically affected by parity, ranging from $1 \%$ for first parity to nearly $10 \%$ during later parities (Table 2).

Cows carrying twin pregnancies can be accurately identified using transrectal ultrasonography by 40 to 55 d post AI (Echternkamp and Gregory, 1991; Davis and Haibel, 1993; Dobson et al., 1993). When conducting an early diagnosis for twins, the entire length of both uterine horns must be carefully scanned to ensure that an embryo is not missed. Because the majority of twinning in dairy cattle occurs due to double ovulations (Wiltbank et al., 2000), the presence of two or more CL on the ovaries at the time of pregnancy diagnosis is an excellent indicator of cows with an increased risk of conceiving twins. Overall, the incidence of double ovulation in lactating dairy cows after synchronization of ovulation using Ovsynch was $14.1 \%$ (Fricke et al., 1998), and the frequency of double ovulation was nearly threefold greater for cows with greater than average milk production near the time of AI than for cows with less than average milk production near the time of AI (Fricke and Wiltbank, 1999).

Several management scenarios could be considered upon identification of a cow carrying twins including culling, abortion and rebreeding, or continued management until parturition (Fricke, 2001). Continued management of the cow could be avoided either by culling the cow or by aborting the twin pregnancy, usually through administration of an ecbolic agent such as $\mathrm{PGF}_{2 \alpha}$. Several factors would argue against aborting a twin pregnancy with the intent of rebreeding the cow. First, although the calving interval would vary widely among cows subjected to abortion, the estimated average calving interval of cows subjected to induced abor- 
Table 2. Effect of parity on twinning rate $(\%)$ in dairy cattle. ${ }^{1}$

\begin{tabular}{|c|c|c|c|c|c|c|c|c|}
\hline \multirow[b]{2}{*}{$\operatorname{Ref}^{2}$} & \multirow{2}{*}{$\begin{array}{l}\text { No. of } \\
\text { calvings }\end{array}$} & \multicolumn{6}{|c|}{ Parity } & \multirow{2}{*}{$\begin{array}{l}\text { All } \\
\text { parities }\end{array}$} \\
\hline & & 1 & 2 & 3 & 4 & 5 & 6 & \\
\hline 1 & 937 & 0.7 & 5.0 & 4.2 & 5.0 & 7.0 & $6.7^{3}$ & 4.2 \\
\hline 2 & 7387 & 1.3 & 4.4 & 5.3 & 4.6 & 5.8 & 6.0 & 4.6 \\
\hline 3 & 11,951 & 0.8 & 2.7 & 4.1 & 4.5 & 4.9 & $4.8^{3}$ & 3.2 \\
\hline 4 & 19,755 & 0.9 & 2.1 & 3.5 & 3.4 & 3.7 & 3.2 & 2.5 \\
\hline 5 & 24,843 & 1.0 & 7.0 & 7.5 & 7.9 & $9.1^{\mathrm{b}}$ & $\ldots$ & 4.2 \\
\hline 6 & 19,497 & 1.3 & 6.0 & $9.4^{\mathrm{b}}$ & & & & \\
\hline 7 & 52,362 & 1.0 & 2.9 & 3.2 & 3.9 & 3.3 & $4.1^{\mathrm{b}}$ & 2.4 \\
\hline
\end{tabular}

${ }^{1}$ Adapted from Wiltbank et al., 2000.

${ }^{2}$ Reference: 1 = Pfau et al., 1948; 2 = Erb and Morrison, 1959; $3=$ Nielen et al., 1989; $4=$ Eddy et al., 1991; 5 = Ryan and Boland, 1991; 6 = Berry et al., 1994; 7 = Kinsel et al., 1998.

${ }^{3}$ Includes all cows $\geq$ the parity listed.

tion and rebreeding would exceed $500 \mathrm{~d}(\sim 18 \mathrm{mo})$ based on average reproductive performance and management indices for lactating cows (Fricke, 2001). Second, the risk for a twin pregnancy during the subsequent gestation is increased because cows calving twins are at greater risk for subsequent twinning (Nielen et al., 1989). Third, establishing pregnancy in lactating dairy cows is difficult, and a pregnancy represents an inherent value to the dairy farm that is forfeited by electively aborting the pregnancy. Finally, cows carrying twins experience greater rates of early embryonic loss than cows carrying singletons and, on occasion, loose one fetus while maintaining the other (Day et al., 1995). Elective abortion of a twin pregnancy early during gestation that may result in the birth of a singleton calf at parturition is not a sound management practice. Based on these considerations and depending on the value of the dam and calf, culling to avoid continued management of a cow carrying twins is a better alternative to aborting the pregnancy. At present, information on twinning management in dairy cattle is inadequate, and further research is needed to make sound management decisions regarding twinning (Fricke, 2001).

\section{Determination of Fetal Sex}

Transrectal ultrasound can be used to detect the sex of bovine fetuses in utero. Sex is determined by evaluating the morphology and location of the genital tubercle using ultrasound and is a reliable and accurate method for sex determination beginning on d 55 to 60 of gestation (Curran et al., 1989). Because the reproductive tract and conceptus descend beyond the pelvic rim and into the abdominal cavity as gestation ensues, it becomes increasingly difficult to physically reach the fetus using a transrectal approach during later stages of gestation. Generally, a greater level of operator experience and proficiency is required for sex determination using ultrasound compared with that required for early pregnancy diagnosis or examination of ovarian structures.

In a production dairy system, determination of fetal sex is useful when combined with a management decision or strategy that justifies the expense of fetal sexing. In other words, a dairy producer who pays for information regarding fetal sex must economically justify the usefulness of that information. Fulfilling sales contract obligations regarding the sex of a calf carried by a pregnant cow to be sold is one scenario that may justify this expense. If the sex of a calf is a determining factor for culling decisions regarding a pregnant cow, fetal sexing might also be justified. In contrast, the cost associated with fetal sexing is unwarranted if the information is not used to make a management decision. Because of the economic and management considerations associated with fetal sexing, routine fetal sexing of all pregnant cows in a herd will not likely become a standard reproductive management practice unless bovine practitioners choose to conduct fetal sexing at little or no additional expense beyond pregnancy diagnosis.

\section{DIAGNOSTIC LIMITATIONS OF ULTRASONIC IMAGING}

Under most circumstances, practical application of ultrasound for routine reproductive management on a dairy farm consists of a single ultrasound examination conducted at a given point in time as opposed to serial ultrasound examinations. The physiological status of a follicle (e.g., dominant, subordinate, growing, regressing) or corpus luteum cannot be determined during a single ultrasound examination. In addition, ultrasonic imaging aids in distinguishing anatomical attributes of a structure but confers little information regarding physiological or endocrine status. For example, ovarian cysts can be categorized by anatomical attributes such as diameter and presence or absence of 
luteal tissue; however, information regarding functionality such as plasma hormone concentrations cannot be conferred. One exception would be the visualization of a fetal heartbeat as a diagnostic indicator of a viable fetus. The diagnostic limitation of ultrasonic imaging becomes important especially when the limitation is exceeded and an incorrect therapy or reproductive intervention is recommended. A thorough understanding of ovarian physiology and the mechanisms by which hormonal programs succeed or fail is critical for correct interpretation of ultrasonic imaging information.

\section{ECONOMIC CONSIDERATIONS OF ULTRASOUND}

Few economic analyses on the use of ultrasonography for reproductive management of dairy cattle have been published to date. However, economic assessment of strategies for early detection of nonpregnancy using other technologies including milk progesterone tests, pressure-mounted heat detection devices, and rectal palpation showed that the earlier nonprenancy was accurately and efficiently detected, the greater the economic return (Oltenacu et al., 1990). Because nonpregnancy can be established 7 to $14 \mathrm{~d}$ earlier post AI when using ultrasound compared with rectal palpation, nonpregnant cows can be detected earlier and returned to AI service, thereby improving the pregnancy rate through an increased AI service rate. Thus, early identification of nonpregnancy post AI coupled with rapid return of nonpregnant cows to AI service may be an economically profitable strategy for a dairy farm.

Ultrasound has previously been reported to be an economically profitable reproductive management strategy for dairy farms (DesCôteaux, and Fetrow, 1998). Economic models were structured to evaluate the annual impact of ultrasonography in reducing average days open. The models included the cost and depreciation of ultrasound equipment, $70 \%$ pregnant cows at initial pregnancy examinations, and a cost of each day open past $100 \mathrm{DIM}$ of $\$ 4.00$. The estimated breakeven costs of ultrasound examinations conducted weekly, bimonthly, and monthly were $\$ 8.40, \$ 16.80$, and $\$ 36.00$, respectively (DesCôteaux, and Fetrow, 1998). These authors concluded that experienced veterinarians could easily pay back their investment in an ultrasound machine within $3 \mathrm{yr}$ when charging half of the breakeven cost of ultrasound while servicing 15 well-managed 100 cow dairies (DesCôteaux, and Fetrow, 1998). Furthermore, as the proportion of pregnant cows at pregnancy evaluation decreases below 70\%, the economic impact of ultrasound increased (DesCôteaux, and Fetrow, 1998). Despite this report, however, a more thorough evaluation of the economics of ultrasound use in conjunction with timed insemination protocols must be undertaken before use of ultrasound can be justified for reproductive management of dairy cattle.

\section{INTEGRATION OF ULTRASOUND INTO THE DAIRY INDUSTRY}

\section{Integrated Reproductive Management Strategies}

New technologies to identify nonpregnant dairy cows early post AI may play a key role in a reproductive management strategy for commercial dairy farms. When using ultrasound for early pregnancy diagnosis, emphasis must be given to identifying nonpregnant rather than pregnant cows. Coupling a nonpregnancy diagnosis with a management decision to quickly reinitiate AI service improves reproductive efficiency and pregnancy rate by decreasing the interval between $\mathrm{AI}$ services, thereby increasing AI service rate. Because AI conception rates of high producing lactating dairy cows are reported to be $40 \%$ or less (Pursley et al., 1997; Fricke et al., 1998), $60 \%$ or more of cows will fail to conceive to an AI service and, therefore, will require a resynchronization strategy for aggressively initiating a subsequent AI service. Ovsynch, a protocol for synchronizing ovulation in lactating dairy cows, uses injections of $\mathrm{GnRH}$ and $\mathrm{PGF}_{2 \alpha}$ (Pursley et al., 1995, 1997) and is an effective method for hormonally programming cows to receive a timed AI service. Hormonal resynchronization systems that program nonpregnant cows to receive a subsequent AI service need to be developed and assessed to aggressively manage reproduction in lactating dairy cows.

The upper protocol in Figure 1 shows a scenario for combining use of Ovsynch and early pregnancy diagnosis using ultrasound. Groups of cows past the voluntary waiting period would receive their first postpartum insemination after synchronization of ovulation using Ovsynch. This would dramatically reduce median days to first AI by eliminating estrus detection for the first postpartum breeding. On d 25 post AI, nonpregnant cows would be identified using ultrasound, and would receive the first $\mathrm{GnRH}$ injection for resynchronization using Ovsynch. This would result in an average interval between services of $35 \mathrm{~d}$ for cows requiring resynchronization. The lower protocol in Figure 1 shows a more aggressive scenario for combining use of Ovsynch and early pregnancy diagnosis using ultrasound. Groups of cows past the voluntary waiting period would receive their first postpartum insemination after synchronization of ovulation using Ovsynch. On d 18 post AI, all cows would receive an injection of $\mathrm{GnRH}$ regardless of their pregnancy status. Ultrasound would be used on d 25 to identify nonpregnant cows, which would receive a $\mathrm{PGF}_{2 \alpha}$ injection for resynchronization using Ovsynch. 


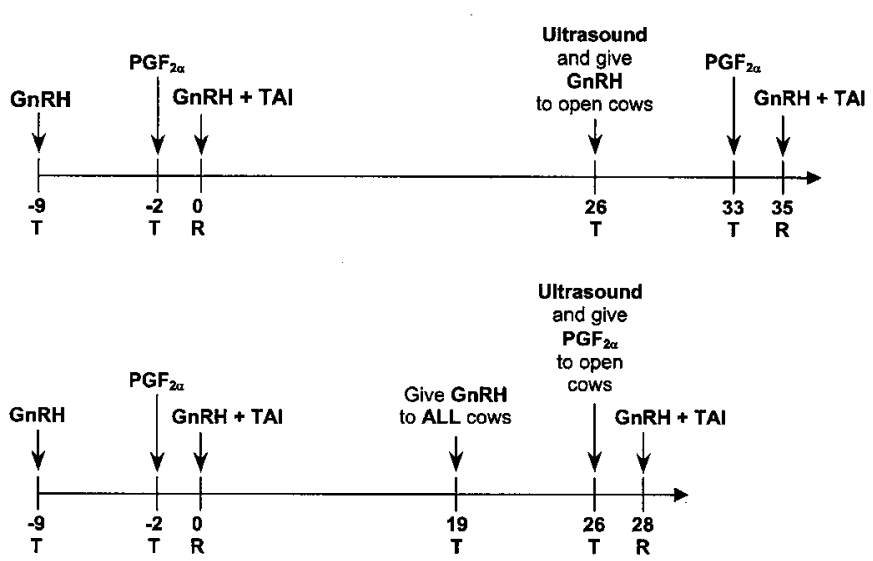

Figure 1. Two theoretical strategies for aggressive reproductive management protocols for combining timed AI (Ovsynch) with early pregnancy diagnosis using ultrasound. Note that hormone injections are scheduled for Tuesdays $(\mathrm{T})$ and Thursdays $(\mathrm{R})$, ultrasound examinations for Tuesdays (T), and timed AI (TAI) for Thursdays (R). Average interval between timed AI services would be $35 \mathrm{~d}$ (upper protocol) or $28 \mathrm{~d}$ (lower protocol) for cows requiring resynchronization. Note that these protocols are meant to illustrate the potential for aggressive resynchronization of nonpregnant cows after an initial timed AI service and must first be empirically tested before they are implemented on dairy farms.

It is important to note that administration of $\mathrm{GnRH}$ to pregnant cows for resynchronization of ovulation after a timed AI has been shown to increase early embryonic loss compared with pregnant cows not receiving GnRH (Moreira et al., 2000b). Conception rate and embryonic loss may vary due to the stage of follicular development at the time of resynchronization using GnRH similar to that shown for initiation of Ovsynch during the estrus cycle in dairy cattle (Moreira et al., 2000a; Vasconcelos et al., 1999). Thus, the protocols shown in Figure 1 must first be empirically tested before they are implemented in the dairy industry and are meant to illustrate the potential for aggressive resynchronization of nonpregnant cows after an initial timed AI service. Further research into the efficacy of protocols that combine timed AI with ultrasonography for aggressive reproductive management of dairy cattle is under way.

\section{The Role of Bovine Practitioners}

Currently, the use of ultrasound by bovine practitioners for routine reproductive management on dairy farms is limited. Veterinarians serve as a key information source for US dairy producers with nearly $80 \%$ of dairy producers citing veterinarians as a very important source of information for making health care decisions for their operations (NAHMS, 1996). Furthermore, $98.1 \%$ of dairy producers surveyed used a veteri- narian to diagnose or treat dairy animals on their operation in 1995 and, of those operations that used a veterinarian, $74.4 \%$ used their veterinarian for reproductive consultation/services (NAHMS, 1996). Because of their role in reproductive management decisions made on dairy farms, effective Extension efforts in dairy cattle reproduction must include veterinarians to effect widespread change in the dairy industry. On average, each bovine veterinarian in Wisconsin has the potential to impact 36 dairy producers (based on 18,000 dairy farms and approximately 500 dairy veterinarians). Although dairy producers can purchase their own ultrasound machine and conduct reproductive examinations on their own cows, they generally lack the knowledge, training, and experience needed to adequately perform such examinations. Furthermore, veterinarians are currently the only group who can legally perform reproductive ultrasound examinations for hire on dairy farms in Wisconsin and most other states in the United States.

\section{Bovine Reproductive Ultrasound Workshops}

Development of Extension education programs to train bovine practitioners to use ultrasound for routine reproductive examinations is a critical step toward implementation of ultrasound technology into the dairy industry. In 1999, an Extension education workshop was developed and implemented in Wisconsin to train bovine practitioners in the practical applications of ultrasound for reproductive management of dairy cattle. The structure of the workshop provides timely, research-based reproductive information and practical hands-on ultrasound experience in an integrated manner.

To date, veterinarians from 20 different US states and 2 Canadian provinces have attended the Bovine Reproductive Ultrasound Workshops held in Wisconsin. That veterinarians travel from across the United States and Canada to attend these workshops in Wisconsin underscores the widespread demand for such training and the lack of adequate training opportunities in other regions of the country. On-farm Extension programs that bring the university together with veterinarians and individual farm owners and operators provide the structure from which significant change in the dairy industry can occur. The concept behind the Bovine Reproductive Ultrasound Workshops draws from the fundamental basis upon which university Extension and the Land Grant System were founded: to enhance the application of useful and practical information beyond the university campus through cooperative Extension efforts with states and local communities (NASULG, 1995). 


\section{CONCLUSION}

As a research tool, transrectal ultrasound has revolutionized our understanding of reproductive biology. As a management tool, transrectal ultrasound may provide a diagnostic tool for improving reproductive management in dairy operations. Although there are many potential applications of ultrasound for use in reproductive management of dairy cattle, combining ultrasound for early pregnancy diagnosis with timed AI along with early detection of twin pregnancies will likely result in the most widespread uses of this technology. Development of integrated reproductive management systems that combine ultrasound with new and existing reproductive technologies will further enhance the practical applications of ultrasonography. Further research on the efficacy of protocols that integrate ultrasonography with timed AI protocols for resynchronzation of ovulation, differential management strategies for cows carrying twin fetuses, and thorough economic analyses on the use of ultrasound for reproductive management of dairy cattle must be conducted before widespread integration of ultrasound occurs in the dairy industry.

\section{REFERENCES}

Ball, P. J. H., and D. D. N. Logue. 1994. Ultrasound diagnosis of pregnancy in cattle. Vet. Rec. 134:532.

Battocchio, M., G. Gabai, A. Mollo, M. C. Veronesi, F. Soldano, G. Bono, and F. Cairoli. 1999. Agreement between ultrasonographic classification of the CL and plasma progesterone concentration in dairy cows. Theriogenology 51:1059-1069.

Baxter, S. J., and W. R. Ward. 1997. Incidence of fetal loss in dairy cattle after pregnancy diagnosis using an ultrasound scanner. Vet. Rec. 140:287-288.

Beerepoot, G. M. M., A. A. Dykhuizen, M. Mielen, and Y. H. Schukken. 1992. The economics of naturally occurring twinning in dairy cattle. J. Dairy Sci. 75:1044-1051.

Berry, S. L., A. Ahmadi, and M. C. Thurmond. 1994. Periparturient disease on large, dry lot dairies: interrelationships of lactation, dystocia, calf number, calf mortality, and calf sex. J. Dairy Sci. 77(Suppl. 1):379. (Abstr.).

Curran, S., R. A. Pierson, and O. J. Ginther. 1986. Ultrasonographic appearance of the bovine conceptus from d 20 through 60. JAVMA 189:1295-1302.

Curran, S., J. P. Kastelic, and O. J. Ginther. 1989. Determining sex of the bovine fetus by ultrasonic assessment of the relative location of the genital tubercle. Anim. Reprod. Sci. 19:217-227.

Davis, M. E., and G. K. Haibel. 1993. Use of real-time ultrasound to identify multiple fetuses in beef cattle. Theriogenology 40:373382.

Day, J. D., L. D. Weaver, and C. E. Franti. 1995. Twin pregnancy diagnosis in Holstein cows: Discriminatory powers and accuracy of diagnosis by transrectal palpation and outcome of twin pregnancies. Can. Vet. J. 36:93-97.

Dawson, F. L. M. 1975. Accuracy of rectal palpation in the diagnosis of ovarian function in the cow. Vet. Rec. 96:218-220.

DesCôteaux, L., and J. Fetrow. 1998. Does it pay to use an ultrasound machine for early pregnancy diagnosis in dairy cows? Proc. AABP Annu. Mtg., Spokane, WA. Vol. 31:172-174.

Dobson, H., T. G. Rowan, I. S. Kippax, and P. Humblot. 1993. Assessment of fetal number, and fetal and placental viability throughout pregnancy in cattle. Theriogenology 40:411-425.
Echternkamp, S. E., and K. E. Gregory. 1991. Identification of twin pregnancies in cattle by ultrasonography. J. Anim. Sci. 69(Suppl. 1):220. (Abstr.).

Eddy, R. G., O. Davies, and C. David. 1991. An economic assessment of twin births in British dairy herds. Vet. Rec. 129:526-529.

Erb, R. E., and R. A. Morrison. 1959. Effects of twinning on reproductive efficiency in a Holstein-Fresian herd. J. Dairy Sci. 42:512519.

Farin, P. W., R. S. Youngquist, J. R. Parfet, and H. A. Garverick. 1990. Diagnosis of follicular cysts in dairy cows by sector scan ultrasonography. Theriogenology 34:633-642.

Farin, P. W., R. S. Youngquist, J. R. Parfet, and H. A. Garverick. 1992. Diagnosis of luteal and follicular ovarian cysts by palpation per rectum and linear-array ultrasonography in dairy cows. JAVMA 200:1085.

Filteau, V., and L. DesCôteaux. 1998. Predictive values of early pregnancy diagnosis by ultrasonography in dairy cattle. Proc. AABP Annu. Mtg., Spokane, WA. Vol. 31:170-171.

Fricke, P. M., J. N. Guenther, and M. C. Wiltbank. 1998. Efficacy of decreasing the dose of GnRH used in a protocol for synchronization of ovulation and timed AI in lactating dairy cows. Theriogenology 50:1275-1284.

Fricke, P. M., and M. C. Wiltbank. 1999. Effect of milk production on the incidence of double ovulation in dairy cows. Theriogenology $52: 1133-1143$.

Fricke, P. M. 2001. Review: Twinning in dairy cattle. Prof. Anim. Sci. 17:61-67.

Galland, J. C., L. A. Offenbach, and M. F. Spire. 1994. Measuring the time needed to confirm fetal age in beef heifers using ultrasonographic examination. Vet. Med. 89:795-804.

Ginther, O. J. 1995. Ultrasonic imaging and animal reproduction. Equiservices Publishing, Cross Plains, WI.

Ginther, O. J., M. C. Wiltbank, P. M. Fricke, J. R. Gibbons, and K. Kot. 1996. Minireview. Selection of the dominant follicle in cattle. Biol. Reprod. 55:1187-1194.

Griffin, P. G., and O. J. Ginther. 1992. Research applications of ultrasonic imaging in reproductive biology. J. Anim. Sci. 70:953-972.

Kastelic, J. P., D. R. Bergfelt, and O. J. Ginther. 1990a. Relationship between ultrasonic assessment of the corpus luteum and plasma progesterone concentrations in heifers. Theriogenology 33:1269-1278.

Kastelic, J. P., R. A. Pierson, and O. J. Ginther. 1990b. Ultrasonic morphology of corpora lutea and central luteal cavities during the estrous cycle and early pregnancy in heifers. Theriogenology 34:487-498.

Kastelic, J. P., D. R. Bergfelt, and O. J. Ginther. 1991. Ultrasonic detection of the conceptus and characterization of intrauterine fluid on days 10 to 22 in heifers. Theriogenology 35:569-581.

Kinsel, M. L., W. E. Marsh, P. L. Ruegg, and W. G. Etherington. 1998. Risk factors for twinning. J. Dairy Sci. 81:989-993.

Mee, J. F., D. P. Ryan, and T. Condon. 1994. Ultrasound diagnosis of pregnancy in cattle. Vet. Rec. 134:532.

Meintjes, M., M. S. Bellow, J. R. Broussard, J. B. Paul, and R. A. Godke. 1993. Transvaginal aspiration of bovine oocytes from hormone-treated pregnant beef cattle for IVF. Theriogenology 39:266. (Abstr.).

Moreira, F., R. L. de la Sota, T. Diaz, and W. W. Thatcher. 2000a. Effect of day of the estrous cycle at the initiation of a timed artificial insemination protocol on reproductive responses in dairy heifers. J. Anim. Sci. 78:1568-1576.

Moreira, F., C. A. Risco, M. F. A. Pires, J. D. Ambrose, M. Drost, and W. W. Thatcher. 2000b. Use of bovine somatotropin in lactating dairy cows receiving timed artificial insemination. J. Dairy Sci. 83:1237-1247.

NAHMS. 1996. United States Department of Agriculture, National Animal Health Monitoring System. Part I: Reference of 1996 Dairy Management Practices. United States Government Printing Office, Washington, DC.

NASULG. 1995. National Association of State Universities and LangGrant Colleges. Office of Public Affairs Publication, Washington, DC. 
Nielen, M., Y. H. Schukken, D. T. Scholl, H. J. Wilbrink, and A. Brand. 1989. Twinning in dairy cattle: a study of risk factors and effects. Theriogenology 32:845-862.

Oltenacu, P. A., Ferguson, J. D., A. J. Lednor. 1990. Economic evaluation of pregnancy diagnosis in dairy cattle: a decision analysis approach. J. Dairy Sci. 73:2826-2831.

Paisley, L. G., W. D. Mickelsen, and O. L. Frost. 1978. A survey of the incidence of prenatal mortality in cattle following pregnancy diagnosis by rectal palpation. Theriogenology 9:481-489.

Pfau, K. O., J. W. Bartlett, and C. E. Shuart. 1948. A study of multiple births in a Holstein-Friesian herd. J. Dairy Sci. 31:241-254.

Pierson, R. A., and O. J. Ginther. 1988. Ultrasonic imaging of the ovaries and uterus in cattle. Theriogenology 29:21-37.

Pieterse, M. C., K. A. Kappen, T. A. Kruip, and M. A. M. Taverne. 1988. Aspiration of bovine oocytes during transvaginal ultrasound scanning of the ovaries. Theriogenology 30:751-762.

Pieterse, M. C., O. Szenci, A. H. Willemse, C. S. A. Bajcsy, S. J. Dieleman, and M. A. M. Taverne. 1990a. Early pregnancy diagnosis in cattle by means of linear-array real-time ultrasound scanning of the uterus and a qualitative and quantitative milk progesterone test. Theiogenology 33:697-707.

Pieterse, M. C., M. A. Taverne, T. A. Kruip, and A. H. Willemse. 1990b. Detection of corpora lutea and follicles in cows: a comparison of transvaginal ultrasonography and rectal palpation. Vet. Rec. 156:552-554.

Pieterse, M. C., P. L. A. M. Vos, T. A. Kruip, Y. A. Wurth, T. H. van Beneden, A. H. Willemse, and M. A. M. Taverne. 1991. Transvaginal ultrasound guided follicular aspiration of bovine oocytes. Theriogenology 35:19-24.

Pursley, J. R., M. O. Mee, and M. C. Wiltbank. 1995. Synchronization of ovulation in dairy cows using $\mathrm{PGF}_{2 \alpha}$ and $\mathrm{GnRH}$. Theriogenology 44:915-923.

Pursley, J. R., M. R. Kosorok, and M. C. Wiltbank. 1997. Reproductive management of lactating dairy cows using synchronization of ovulation. J. Dairy Sci. 80:301-306.
Ryan, D. P., and M. P. Boland. 1991. Frequency of twin births among Holstein-Friesian cows in a warm dry climate. Theriogenology $36: 1-10$.

Singh, J., R. A. Pierson, and G. P. Adams. 1997. Ultrasound image attributes of the bovine corpus luteum: structural and functional correlates. J. Reprod. Fertil. 109:35-44.

Smith, M. W., and J. S. Stevenson. 1995. Fate of the dominant follicle, embryonal survival, and pregnancy rates in dairy cattle treated with prostaglandin $\mathrm{F}_{2 \alpha}$ and progestins in the absence or presence of a functional corpus luteum. J. Anim. Sci. 73:3743-3751.

Spicer, L. J., and S. E. Echternkamp. 1986. Ovarian follicular growth, function and turnover in cattle: A review. J. Anim. Sci. $62: 428-451$.

Szenci, O., G. Gyulai, P. Nagy, L. Kovacs, J. Varga, and M. A. M. Taverne. 1995. Effect of uterus position relative the pelvic inlet on the accuracy of early bovine pregnancy diagnosis by means of ultrasonography. Vet. Q. 17:37-39.

Vaillancourt, D., C. J. Vierschwal, D. Ogwu, R. G. Elmore, C. E. Martin, A. J. Sharp, and R. S. Youngquist. 1979. Correlation between pregnancy diagnosis by membrane slip and embryonic mortality. JAVMA 175:466.

Vasconcelos, J. L. M., R. W. Silcox, J. A. Lacerda, J. R. Pursley, and M. C. Wiltbank. 1997. Pregnancy rate, pregnancy loss, and response to heat stress after $\mathrm{AI}$ at two different times from ovulation in dairy cows. Biol. Reprod. 56(Suppl 1):140. (Abstr.).

Vasconcelos, J. L. M., R. W. Silcox, G. J. Rosa, J. R. Pursley, and M. C. Wiltbank. 1999. Synchronization rate, size of the ovulatory follicle, and pregnancy rate after synchronization of ovulation beginning on different days of the estrous cycle in lactating dairy cows. Theriogenology 52:1067-1078.

Wiltbank, M. C., P. M. Fricke, S. Sangsritavong, R. Sartori, and O. J. Ginther. 2000. Mechanisms that prevent and produce double ovulation in dairy cattle. J. Dairy. Sci. 83:2998-3007. 